\title{
Evaluation of CrAIN multilayered coatings deposited by PVD magnetron sputtering
}

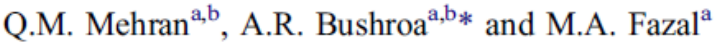 \\ ${ }^{a}$ Faculty of Engineering, Mechanical Engineering Department, University Malaya, Kuala \\ Lumpur 50603, Malaysia; ${ }^{6}$ Center of Advanced Manufacturing and Material Processing, AMMP \\ Center, University Malaya, Kuala Lumpur 50603, Malaysia
}

(Received 12 January 2015; final version received 23 April 2015; accepted 20 May 2015)

\begin{abstract}
The purpose of this experimental work is to evaluate the mechanical and tribological properties of chromium aluminum nitride $(\mathrm{CrAlN})$ coating deposited on hypereutectic Al-Si-alloy. The microstructural, topographical analysis, and composition of CrAlN-coated substrates were examined by using scanning electron microscopy and energy-dispersive spectroscopy, whereas phase formation was analyzed by X-ray Diffractometer (XRD). Atomic force microscopy (AFM) images were taken from the substrate surface before and after the coating. The scratch adhesion of filmto-substrate was measured by using scratch machine. In an effort to understand the critical point, loads were identified by Scratch track in terms of load vs. depth as a function of scan distance. Moreover, the critical load as the beginning of chipping or spallation of the coating was studied. The tribological properties of CrAlN coating were evaluated by pin on disc tribometer at room temperature. XRD analysis showed that CrAIN successfully deposited with a preferential orientation along the (1 111$),\left(\begin{array}{lll}2 & 0 & 0\end{array}\right)$ and $(220)$ peaks. The AFM images of coated sample confirmed that the surface roughness was $\operatorname{lower}\left(R_{\mathrm{a}}=14 \mathrm{~nm}\right)$ as compared to uncoated sample $\left(R_{\mathrm{a}}=46 \mathrm{~nm}\right)$. The hardness of coated hypereutectic Al-Si-alloy was increased about 5.8 times as compared to uncoated sample. The coefficient of friction and wear rate of coated specimen were found to be improved. The coating adhesion strength of $2341 \mathrm{mN}$ was obtained with coating parameters for deposition of DC power $(350 \mathrm{~W})$, RF power $(200 \mathrm{~W})$, temperature $\left(175^{\circ} \mathrm{C}\right)$, and nitrogen flow rate $(5 \%)$.
\end{abstract}

Keywords: hypereutectic Al-Si-alloy; PVD magnetron sputtering; CrAlN-coating; scratch adhesion; tribology

\section{Introduction}

Aluminum and its alloys are now growing applications in the areas which primarily demand light weight and high strength characteristics in materials.[1] Indeed, there are excellent materials that are used to manufacture industrial, automotive, and aerospace components owing to their low density, fracture toughness, and corrosion resistance.[2] Accordingly, automotive manufacturers have been employing hypereutectic Al-Si alloy, especially in engine components such as compressors, pistons, and cylinder blocks. $[1,3]$ Unfortunately, the use of this alloy has disadvantages due to microstructural defects such as coarse eutectic structure, massive amount of silicon contents, and porosity.[1] These significantly reduce the tribological properties. In order to improve, the mechanical and

*Corresponding author. Email: bushroa@um.edu.my 
wear properties can be achieved either by bulk material modification through forming or by heat treatment processes. But with the advent of surface engineering, multiple benefits can be gained without any major processing.[4] For this purpose, the surface properties of aluminum alloys are enhanced by ternary nitride coatings. These coatings are used to supplement the additional properties that are required in wear applications. [5,6] In the recent years, ternary coating has drawn more attraction and attention in the automobile industry, especially for engine components. It has been reported that ternary chromium aluminum nitride (CrAIN) coating exhibited excellent mechanical and tribological properties than conventional binary $\mathrm{CrN}$ and $\mathrm{TiN}$ coatings.[7-9] The addition of $\mathrm{Al}$ content in $\mathrm{CrN}$ phase further enhances its properties by preventing ploughing-induced wear and coating delamination.[10] Until now, CrAIN has been deposited only on ferrous alloys [11-13] and is not reported to be coated on aluminum alloys. In order to yield optimum performance, the first and foremost requirement is that the deposited coating should be effectively bonded and adhered to the substrate. Lackner et al. [14] observed the multilayer coatings to dissipate energy in the layer, deform plastically, and thus restrict the propagation of cracks, hence show higher wear resistance.

There are wide verity of coating processes including physical vapor deposition (PVD), chemical vapor deposition and cathodic arc evaporation methods. Among these, PVD, a commonly applied coating process, produces an extremely fine coating with excellent film properties. It could be used to deposit CrAIN coating by condensation of vaporized metal targets onto the bulk material.[14] The available PVD coating techniques for CrAIN coating are thermal evaporation, [15] ion plating,[12] and magnetron sputtering.[13] The thermal evaporation and ion beam deposition processes may result in poor adhesion and require complex process parameters.[16,17] On the other hand, CrAlN coating deposition through PVD magnetron process is advantageous, since the microstructure instabilities in bulk material is entirely eliminated in high temperature as the coating is carried out well below the distortion temperature.[18] In addition, magnetron sputtering process produces uniform and adherent coatings with controlled stoichiometric ratios. Previously conducted studies employed sputtering either by DC power or by RF power, but to the best of our knowledge; none has reported the combined application of DC and RF power with separate targets of $\mathrm{Cr}$ and $\mathrm{Al}$. In this study, $\mathrm{Cr}$ target was coupled with DC and $\mathrm{Al}$ was with $\mathrm{RF}$ power, as this arrangement allows individual control of the amount of coating material deposited on the substrate. Moreover, deposition process was carried out in reactive and non-reactive gaseous environments.

The scratch adhesion test is a widely accepted process for assessing the mechanical reliability and integrity of the coated surfaces. The performance evaluation of hard coatings deposited on metallic substrate is performed by Rockwell-C diamond stylus as indenter for adhesion strength characterization. The stylus is used because of ease of result interpretation and relatively robust experimental setup. Similarly, in order to avoid premature film-to-substrate boundary failures, chipping, spallation, and delamination, the primary concern is directed towards the maintenance of interfacial bond strength quality. In this work, the scratch adhesion (critical load) of coating-to-substrate was determined by micro-scratch machine equipped with the optical microscopy (OM) to identify the scratch tracks. Hardness, roughness, and tribology tests of uncoated and CrAlN-coated samples were carried out. The microstructural and topographical compositions of coated substrates were also characterized. 


\section{Experimental details}

\subsection{Sample preparation and coating deposition}

In this research work, hypereutectic $\mathrm{Al}-\mathrm{Si}$-alloy was investigated. The material Aluminum-Silicon alloy having chemical composition consisting of $0.11 \% \mathrm{Zn}, 0.07 \%$ $\mathrm{Mn}, 1.64 \% \mathrm{Cu}, 0.06,18 \% \mathrm{Si}, 0.09 \% \mathrm{Cr}$, and $\mathrm{Al}$ balance (in wt.\%) was cut in round samples of $6 \mathrm{~mm}$ thickness and $22 \mathrm{~mm}$ diameter from cylindrical bar with electric discharge wire cutting machine. Samples were grounded with silicon carbide paper of $500,800,1500$, and 2400 grit size and subsequently mirror polished with 3 and $1 \mu \mathrm{m}$ diamond suspended liquid. This resulted in surface roughness $R_{\mathrm{a}}=46 \mathrm{~nm}$ of polished sample. Thereafter, the samples were washed in ultrasonic cleaning bath with acetone for $10 \mathrm{~min}$. Subsequently the samples were rinsed and washed with distilled water and were desiccated using nitrogen in order to avoid contamination.

The CrAlN coatings were deposited on hypereutectic Al-Si-alloy with very thin coating thickness using DC/RF power and magnetron sputtering system (TF450 Sputtering System, SG Control Engineering). High purity chromium (99.99\%) and aluminum (99.99\%) cathode targets were utilized in high purity argon $(99.99 \%)$ and nitrogen $(99.99 \%)$ atmosphere. The substrates were rotating (two-axis rotation) with controllable speed and the targets were mounted above the substrate at about $150 \mathrm{~mm}$. $\mathrm{Cr}$ target was mounted on DC power system whereas RF power was coupled with $\mathrm{Al}$ target. The deposition coating chamber was evacuated to a base pressure of $2.8 \times 10^{-5}$ Torr before introducing the argon gas for sputtering. The samples were radiatively heated at a temperature of $175^{\circ} \mathrm{C}$. Pure $\mathrm{Cr}$ interlayer was deposited on the substrate for $1 \mathrm{~h}$ in order to increase the adhesion strength between second layer CrAIN coatings and substrate. The deposition time for CrAIN (second layer) was adjusted to $2 \mathrm{~h}$ at the constant $\mathrm{Ar}+$ gas flow of $20 \mathrm{sccm}$ into the vacuum chamber. Working pressure at around $4.5 \times 10^{-3}$ depends on the flow rate of $\mathrm{Ar} / \mathrm{N}_{2}$ gases. In magnetron sputtering process, four parameters including (i) DC power, (ii) RF power, (iii) temperature, and (iv) nitrogen $\left(\mathrm{N}_{2}\right)$ are tabulated in Table 1.

\subsection{Microstructural characterization}

The microstructural and topographical analysis of coated substrate layers were characterized by using scanning electron microscopy (SEM) and energy-dispersive spectroscopy (EDX). EDX was basically used to characterize the elemental composition of coated and uncoated sample. The crystalline structure of the CrAlN coating deposited was analyzed using X-ray Diffractometer (XRD) (EMPYREAN, Panalytical X'Pert High Score) with a Cu K-Alpha $(1.54 \AA) \mathrm{K}$-Alpha $45 \mathrm{kV} / 40 \mathrm{~mA} \mathrm{X}$-ray source. The surface roughness was characterized by atomic force microscope (AFM Ambios). Microscopic examinations of the surface were carried using Olympus BX61 light optical microscope (OM) to determine the surface morphology of hypereutectic Al-Si-alloy after PVD CrAIN coating deposition and also to evaluate scratch adhesion test indentation scheme.

Table 1. Deposition parameters for PVD CrAIN coating.

\begin{tabular}{lcccccc}
\hline Coating & $\begin{array}{c}\text { Evacuation } \\
\text { pressure (Torr) }\end{array}$ & $\begin{array}{c}\text { Sputtering } \\
\text { pressure (Torr) }\end{array}$ & $\begin{array}{c}\text { CrAlN } \\
\text { deposition time } \\
(\mathrm{h})\end{array}$ & $\begin{array}{c}\text { DC/RF } \\
\text { power } \\
(\mathrm{W})\end{array}$ & $\begin{array}{c}\text { Temperature } \\
\left({ }^{\circ} \mathrm{C}\right)\end{array}$ & $\begin{array}{c}\mathrm{N}_{2} \\
\text { flow } \\
\text { rate }\end{array}$ \\
\hline CrAlN & $2.8 \times 10^{-5}$ & $4.5 \times 10^{-3}$ & 2 & $350 / 200$ & 175 & $5 \%$ \\
\hline
\end{tabular}




\subsection{Hardness and wear tests}

The hardness of the coating was measured from load-displacement curves achieved by a computer controlled nanoindenter (Hysitron. Inc. nanomechanical test instruments system, Berkovich diamond indentor) using the Oliver and Pharr method.[19] The maximum indentation load $1000 \mu \mathrm{N}$ in steps of $30 \mu \mathrm{N} / \mathrm{s}$ to ensure that at these loads, the indentation depth was kept below $1 / 10$ of the total coating thickness. The time for each loading, holding, and unloading were set at 30,10 , and $30 \mathrm{~s}$, respectively with constant speed. Five nanoindentation tests were made onto the surface and the average result was calculated from the obtained data. The wear tests were conducted using a pinon-disc tester model TR-20LE. The wear tests uncoated and coated substrates were performed under dry sliding conditions at room temperature. The experimental parameters for the pin-on-disc wear tests were as follows: the wear track diameter of $D=40 \mathrm{~mm}$, the normal load of $20 \mathrm{~N}$, a reciprocating frequency of $10 \mathrm{~Hz}$, and amplitude stroke of $2 \mathrm{~mm}$ for $30 \mathrm{~min}$. After test, the substrates were ultrasonically cleaned in ethanol and dried. Besides, weight loss for the samples was determined after wear test with a high precision weight balance 'Denver Instrument' with accuracy of $0.0001 \mathrm{~g}$. The wear rate and coefficient of friction were examined by the friction force and normal loads. The wear tracks formed in the coating were determined by SEM.

\subsection{Scratch testing}

Scratch testing is a quantitative technique to measure the adhesion strength between substrate and coating. The adhesion strength is, commonly referred to as critical load $\left(\mathrm{Lc}_{2}\right)$, defined as total coating failure. Several authors have worked on this system, to evaluate the film-to-substrate critical load and their corresponding failure modes.[20,21] In this research work, the film-to-substrate adhesion was measured by scratch test machine manufactured by Micro Material Ltd (Wrexham, UK) assembled with detection system, motorized stages, penetration depth sensors, optical microscope, acoustic emission, and tangential frictional load sensors. The micro-scratch indenter fitted with a diamond probe of $25 \mu \mathrm{m}$ nominal radius produced the scratch indentation. The indenter was drawn linearly at a speed of $1.20 \mu \mathrm{m} / \mathrm{s}$ across the coating surface with an increasingly step load from $8.7 \mathrm{mN} / \mathrm{s}$ to a maximum limit of $2500 \mathrm{mN} / \mathrm{s}$. Using instrumentation software in single pass scratch testing mode, a scratch track of about $600 \mu \mathrm{m}$ distance was produced. As the load increases during the scratching process, a scratch channel is produced followed by cracking, delamination, and chipping. Thereafter, the scratch response is evaluated in form of abrupt changes in slope of load vs. depth profile. In addition, changes in surface morphology across the scratch track were investigated by $\mathrm{OM}$ to visualize various coating failure mechanisms and to examine coating's adhesive and cohesive properties.

\section{Results and discussion}

\subsection{Coating morphology and elemental composition}

Figure 1(a) and (b) show optical micrographs of uncoated sample and CrAlN-coated sample with magnified view of their outer most surfaces. As can be seen in circular coated specimen of Figure 1(b), an uniform coating without any delamination cracks or craters is observed confirming that the growth process has continued evenly on the entire substrate with an approximate deposition area of $380 \mathrm{~mm}^{2}$. Upon closer examinations at $10-100 \times$ magnifications in Figure 1(b), small black pores emanates as a result 


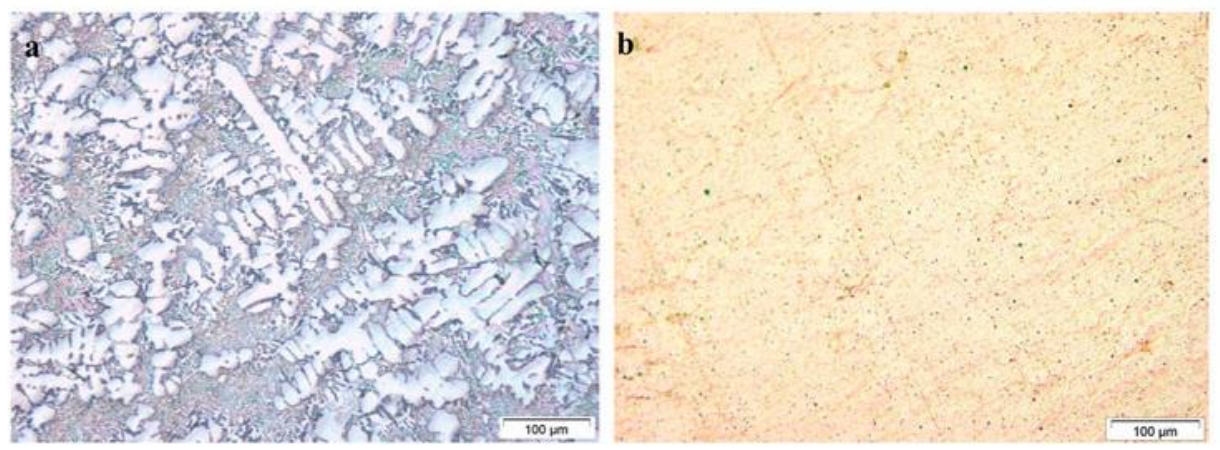

Figure 1. Optical micrographic images for (a) uncoated and (b) coated sample.

of debonding of macro-particles from the coating. These dark spots are pinholes classified as macroscopic defects which may have negligible effect on coating adhesion.[22]

Figure 2(a) depicts the SEM cross-sectional microscopy of CrAIN coating deposited on Al-Si-alloy. The thickness as measured for CrAIN top layer and $\mathrm{Cr}$ interlayer were 1.69 and $1.1 \mu \mathrm{m}$, respectively, contributing to an approximate total coating thickness of $2.79 \mu \mathrm{m}$. Under SEM, the coating exhibits neither columnar nor granular structure. The micrograph shows that the coating is very dense and this compactness makes CrAlN coating a strong candidate in applications where high hardness and adhesion strength is required. Moreover, there are no visible defects at micro level between interlayer and substrate interface, conforming to advantage of PVD processes improving the adhesion strength and wear resistance. According to the EDX, area mapping in Figure 2(b), an uniform atomic composition of $5 \%$ of $\mathrm{N}_{2}, 24 \%$ of $\mathrm{Al}$, and $71 \%$ of $\mathrm{Cr}$ was obtained. Figure 2(b) is showing the diffusion rate of coating layers along with bulk substrate material and EDX cross-sectional line scan, which implies adequate deposition of intended materials. The inter diffusion of $\mathrm{Cr}$ and $\mathrm{Al}$ metals between substrate and interlayer contributes to strong interlock for higher adhesion strength. The chromium interlayer assisted in absorbing oxygen on aluminum substrate, thereby decomposing the native oxide layer on surface of substrate, which consequently increases adhesion. Various authors have reported [23] that pure $\mathrm{Cr}$ interlayer reduces the residual stresses between the Cr-based nitrides and aluminum substrate ultimately leading to a stronger bond between coating and substrate.

The X-ray diffraction patterns of CrAIN coating deposited on Al-Si-alloy substrate are shown in Figure 3. In the diffraction pattern of the CrAlN coating, the rocksalt- crystal type of $\mathrm{CrN}$ crystalline were observed at $\left(37.6^{\circ}\right),\left(44.4^{\circ}\right)$, and $\left(65.7^{\circ}\right)$ with the orientations of (1 11 ), (2 000$)$, and (2 20 ), respectively. The results of $\mathrm{CrN}$ peaks within the CrAlN coating was observed by other researchers.[13,24] The CrN peak, in the present study of CrAlN coating was shifted. It is believed that this phenomenon is due to dissolution of $\mathrm{Al}$ atoms into $\mathrm{CrN}$ lattice by substitution of smallest $\mathrm{Al}$ contents for $\mathrm{Cr}$ sites.[24] This led to reductions in d-spacing as 2.39138 (11 1), 2.03801 (2 00$)$, and 1.46539 (22 0), respectively, resulting in the observed peaks shift. Similar effects are reported by Shah and Jayaganthan. [25]. In order to evaluate the surface morphology and roughness, information for uncoated polished sample and CrAlN-coated sample were characterized by atomic force microscope (AFM). Figure 4(a) and (b) are three-dimensional AFM images taken of a uncoated (sample A) and a CrAIN coated (sample B), respectively. AFM was used in contact mode with the surface scan area set to $60 \times 60 \mu \mathrm{m}^{2}$. For profile 
(a)

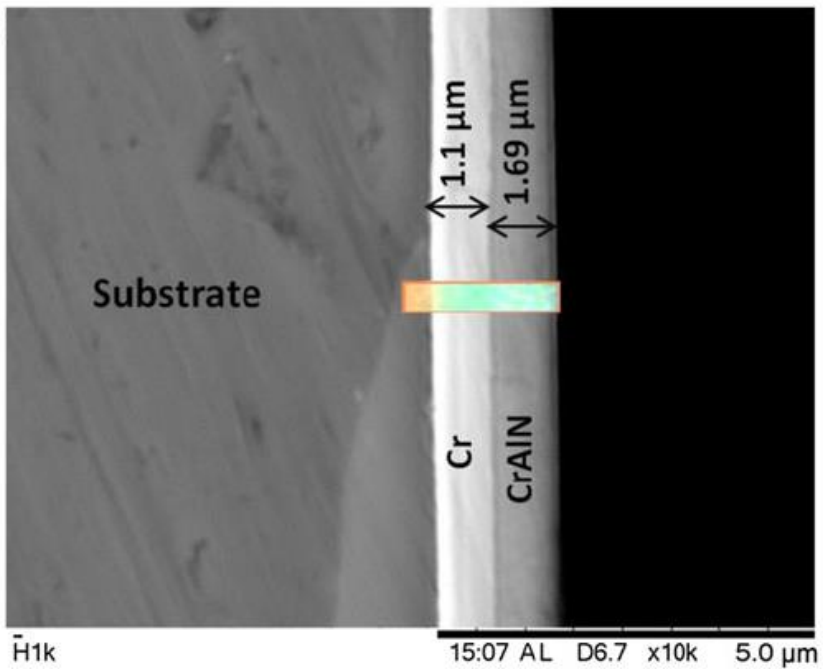

(b)

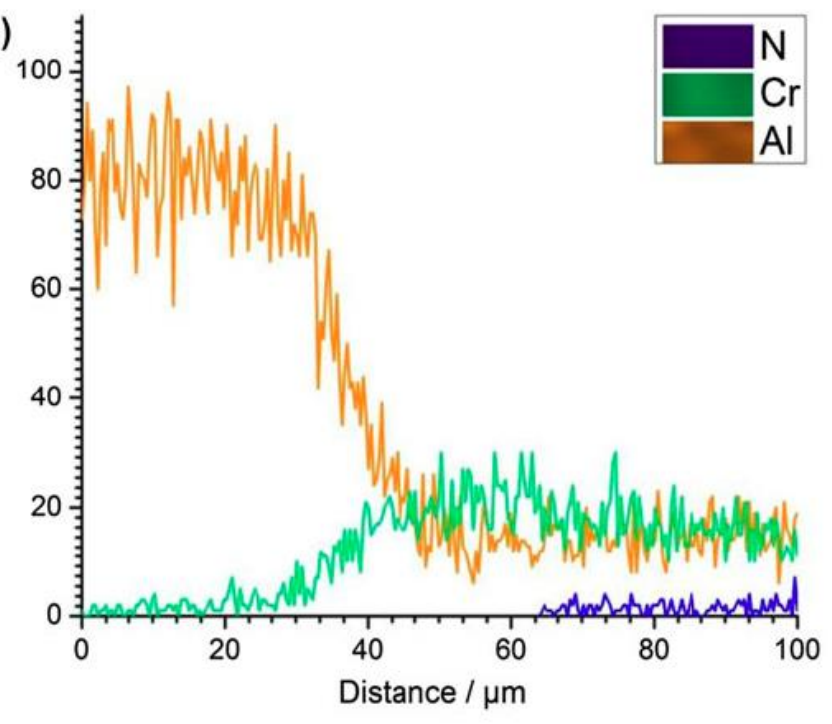

Figure 2. (a) Cross-sectional SEM and EDX micrograph of CrAIN coating on hypereutectic Al-Si-alloy.

surface roughness, $R_{\mathrm{a}}$ (root mean square value) is frequently used to determine the arithmetic means of deviation in height from the profile mean value. The topography, illustrated in Figure 4(a), suggests that the uncoated sample is composed of coarse irregular top surrounded by tiny voided area, while the surface morphology exhibited in Figure 4(b) (coated sample) is composed of smooth surface. In Table 2 shows the surface roughness of uncoated sample is $46 \mathrm{~nm}$, while it is $14 \mathrm{~nm}$ for coated sample, resulting in 3.2 times decrease in the roughness of CrAIN-coated specimen. It can be seen from Figure 4(b), the coating is free from surface delamination, cracks, and craters with minute protruding hillocks spread over the entire area. 


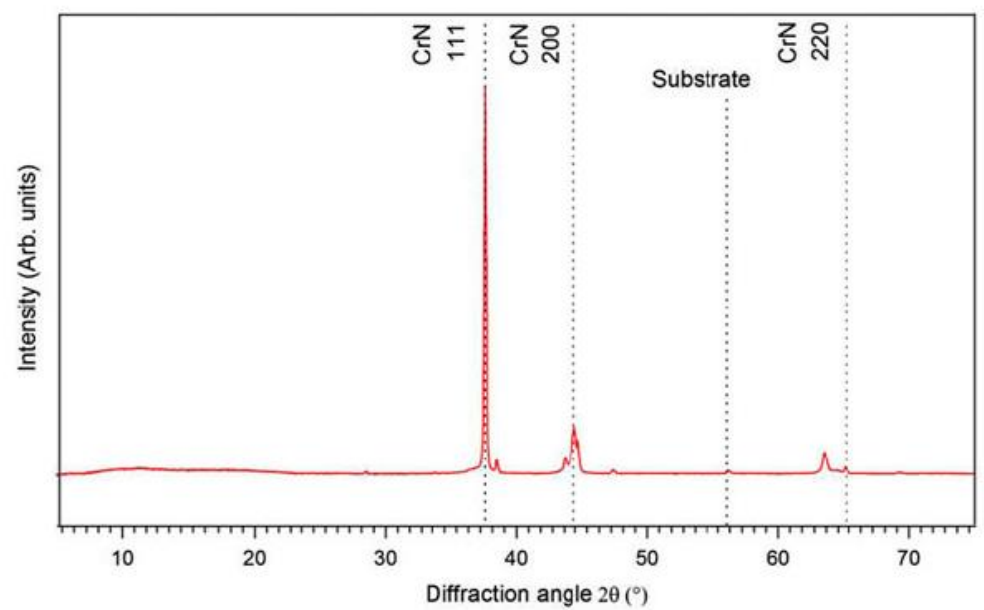

Figure 3. X-ray diffraction patterns of CrAlN coating.
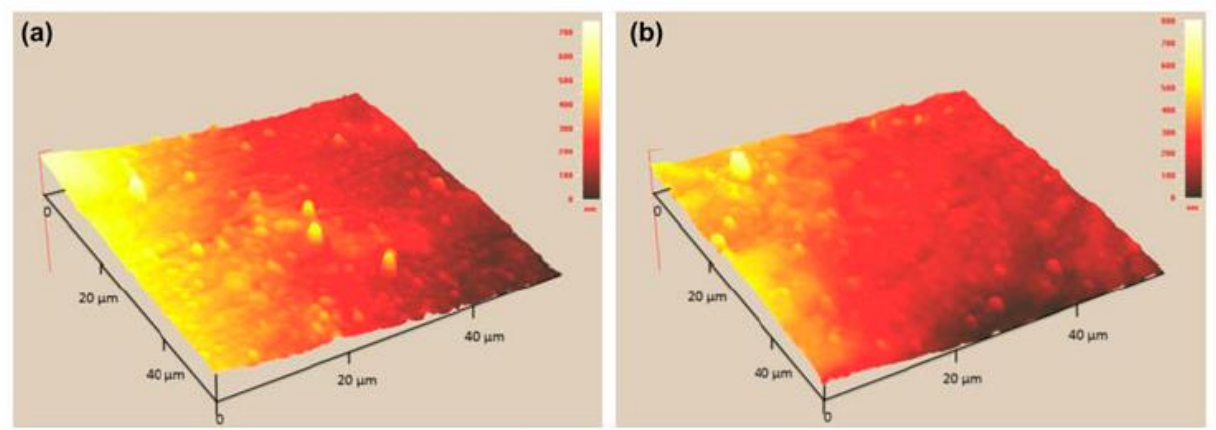

Figure 4. Three-dimensional AFM images of (a) uncoated and (b) CrAIN-coated samples.

Table 2. Comparison of mechanical properties of uncoated and CrAlN-coated samples.

\begin{tabular}{lccc}
\hline Material & Surface roughness $(\mathrm{nm})$ & Hardness $(\mathrm{Gpa})$ & $\begin{array}{c}\text { Adhesion strength } \\
\mathrm{Lc}_{3}(\mathrm{mN})\end{array}$ \\
\hline Hypereutectic Al-Si-alloy & 46 & 0.9 & - \\
CrAIN & 14 & 4.2 & 2,341 \\
\hline
\end{tabular}

\subsection{Hardness and wear analysis}

The hardness was measured for the uncoated and coated substrates by nanoindentation test. Figure 5 shows the continuous force $(\mu \mathrm{N})$ vs. displacement $(\mathrm{nm})$ data obtained from nanoindentation tests performed on coated (interlayer and top layer) and uncoated substrates. The hardness as measured for CrAlN top layer and $\mathrm{Cr}$ interlayer were 4.2 and $1.5 \mathrm{GPa}$, respectively and the hardness value of uncoated substrate was $0.9 \mathrm{GPa}$. It has been noticed that the hardness of multilayered coated sample contributed to an increase 


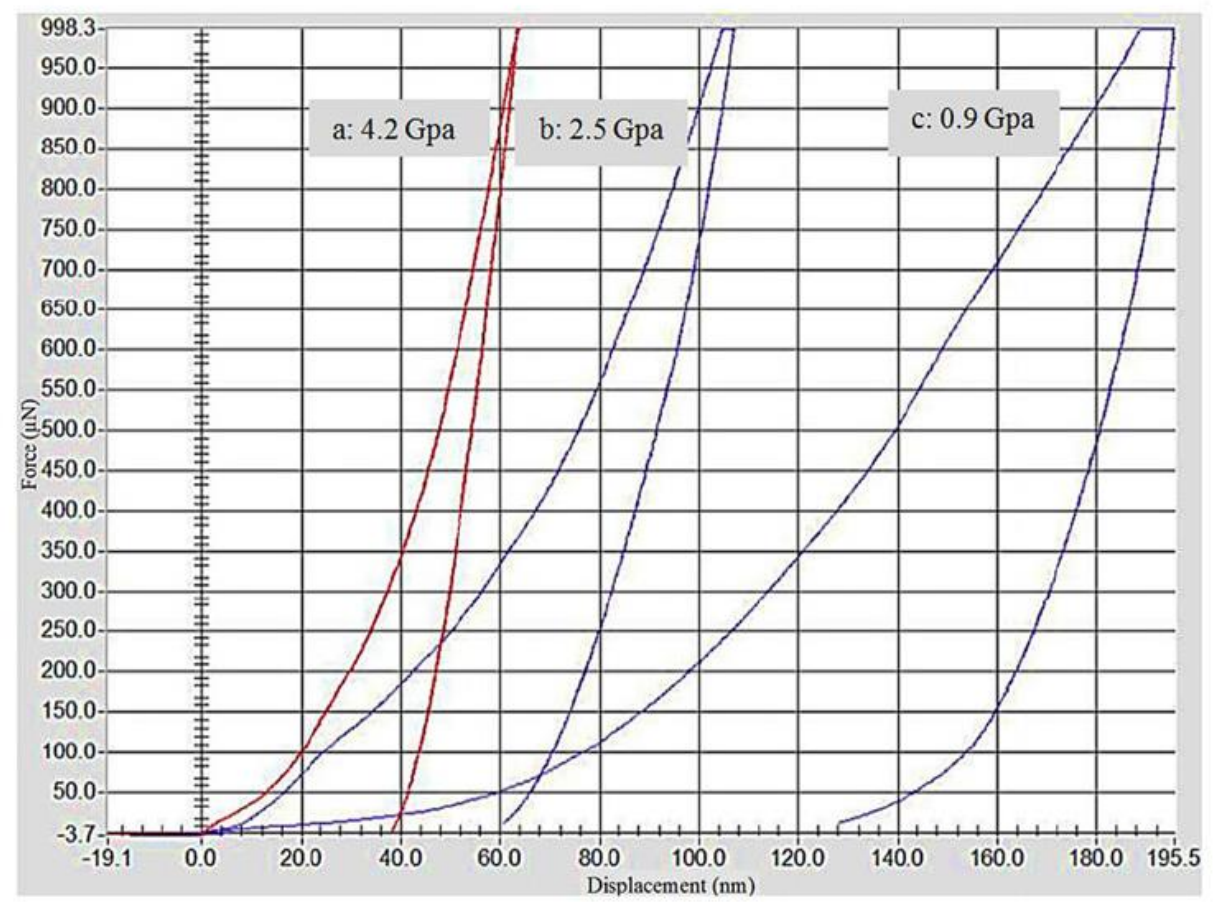

Figure 5. Load-displacement curves of (a) CrAlN-top layer, (b) Cr-interlayer, and (c) uncoated sample.

of approximately 4.7 times than uncoated sample (Table 2). Figure 6 shows the typical kinetic friction coefficient ' $\mu_{\mathrm{k}}$ ' vs. cumulative time curves for hypereutectic Al-Si-alloy and CrAIN under normal load of $20 \mathrm{~N}$. In the transition stage, ' $\mu_{\mathrm{k}}$ ' increased gradually in slope at the beginning and reached a steady-state condition in a short period, which was due to the initial successive wear of the surfaces' micro asperities and enhanced conformity of worn surfaces. Therefore, in the early stages, wear damage occurred due to brittle micro-fractures within surface grains and in the later stages, tribochemical reactions were responsible for wear damage.[26] In the initial stage, the CrAlN-coated sample presented lowest value of coefficient of friction while the uncoated sample presented the highest one. This sudden increase in friction coefficient (Figure 6) was

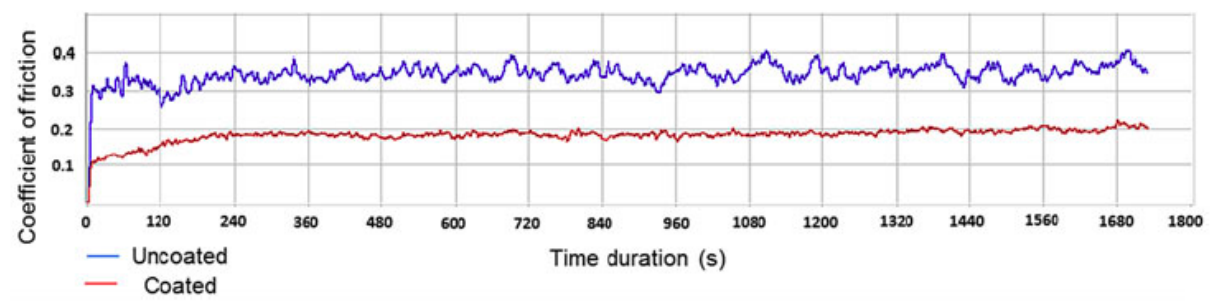

Figure 6. The friction coefficient as a function of cumulative sliding time under normal load of $20 \mathrm{~N}$ for uncoated and coated sample.

\section{Link to Full-Text Articles :}

http://www.tandfonline.com/doi/pdf/10.1080/01694243.2015.1054577 